\title{
OBSERVAÇÕES CITOLÓGICAS EM COFFEA - IV $\left(^{*}\right)$
}

C. A. $e^{\mathbf{K}} \mathbf{r} \mathbf{u}$

A. J. T. Mendes

\section{I - INTRODUÇÃO}

Uma informação preliminar sôbre a ocorrência de um cafeeiro triplóide, obtido pelo cruzamento do $C$. arabica $\mathrm{L} .(2 \mathrm{n}=44)$ com C. canephora Pierre $(2 \mathrm{n}=22)$, foi publicada por Krug (3) em um dos seus artigos sôbre citologia de Coffea. A planta achava-se, nessa ocasião, no início do seu desenvolvimento, e a determinação do número de cromosômios $(2 \mathrm{n}=33)$ foi feita em pontas de raízes. Em metáfase, alguns dos cromosômios maiores do C. canephora puderam ser fàcilmente distinguidos. Em outros artigos sôbre o mesmo assunto, foi sugerido que alguns dos híbridos interespecíficos existentes em Java eram altamente improdutivos devido à sua natureza triplóide, pois se esperava que uma alta esterilidade ocorresse nestas plantas.

O presente artigo confirma a hipótese sôbre a esterilidade dêstes triplóides e dá uma descrição detalhada do comportamento meiósico de seus cromosômios. No decorrer de nossos trabalhos, mais alguns outros híbridos da mesma natureza foram obtidos.

\section{II - CARACTERES MORFOLÓGICOS DE DOIS HÍBRIDOS IN IERESPECÍFICOS}

\section{(Coffea arabica $\times$ C. canephora)}

Os híbridos interespecíficos estudados até o momento são, com relação à maioria dos seus caracteres morfológicos, intermediários às espécies que lhes deram origem. A germinação das sementes híbridas é um tanto retardada e o crescimento inicial das plantas bastante vagaroso, o que pode ser consequência da falta de suficiente tecido nutritivo na semente. A partir de um certo ponto, o crescimento torna-se normal. Nenhum vigor híbrido foi observado.

(*) O original em inglês dêste trabalho foi publicado no "Journal of Genetics", sob o título: "Cytological observations in Coffea - IV".

Jour. of Gen. 39 (2) : 189-203. 1940. 
No Quadro I apresentam-se as dimensões das fôlhas das plantas usadas nos cruzamentos e as das dos seus híbridos, todos cultivados à meia sombra de um ripado; a fig. 1 mostra as diferenças entre as suas flores ( $x \quad 1 / 2)$.

Quadro I

\begin{tabular}{|c|c|c|c|c|c|}
\hline \multirow{2}{*}{$\begin{array}{l}\text { N. o da } \\
\text { árvore }\end{array}$} & \multirow[b]{2}{*}{ Espécies e híbridos } & \multicolumn{4}{|c|}{ DIMENSOEES DAS FÓLHAS } \\
\hline & & $\begin{array}{c}\text { Compto. } \\
(\mathrm{mm})\end{array}$ & $\begin{array}{l}\text { Largura } \\
(\mathrm{mm})\end{array}$ & Índice & $\begin{array}{c}\text { Ângulo das } \\
\text { nervuras }\end{array}$ \\
\hline 45 & $\begin{array}{l}\text { C. arabica var. bourbon } \\
(2 \mathrm{n}=44)\end{array}$ & 131,94 & 53,44 & 2,47 & $57^{\circ}$ \\
\hline $45 \times 37$ & $\begin{array}{l}\text { Híbrido triplćide } \\
\qquad(2 \mathrm{n}=33)\end{array}$ & 172,00 & 71,88 & 2,39 & $63^{\circ}$ \\
\hline 37 & $\begin{array}{l}\text { C. canephora } \\
\qquad(2 n=22)\end{array}$ & 192,50 & 87,92 & 2,19 & $67^{\circ}$ \\
\hline 34 & $\begin{array}{l}\text { C. arabica var. mokka } \\
(2 \mathrm{n}=44)\end{array}$ & 87,40 & 29,16 & 2,99 & $48^{\circ}$ \\
\hline $36 \times 34$ & $\begin{array}{l}\text { Híbrido triplśide } \\
\qquad(2 \mathrm{n}=33)\end{array}$ & 126,34 & 43,92 & 2,88 & $55^{\circ}$ \\
\hline 36 & $\begin{array}{l}\text { C. canephora } \\
\qquad(2 \mathrm{n}=22)\end{array}$ & 210,62 & 88,52 & 2,38 & $69^{\circ}$ \\
\hline
\end{tabular}

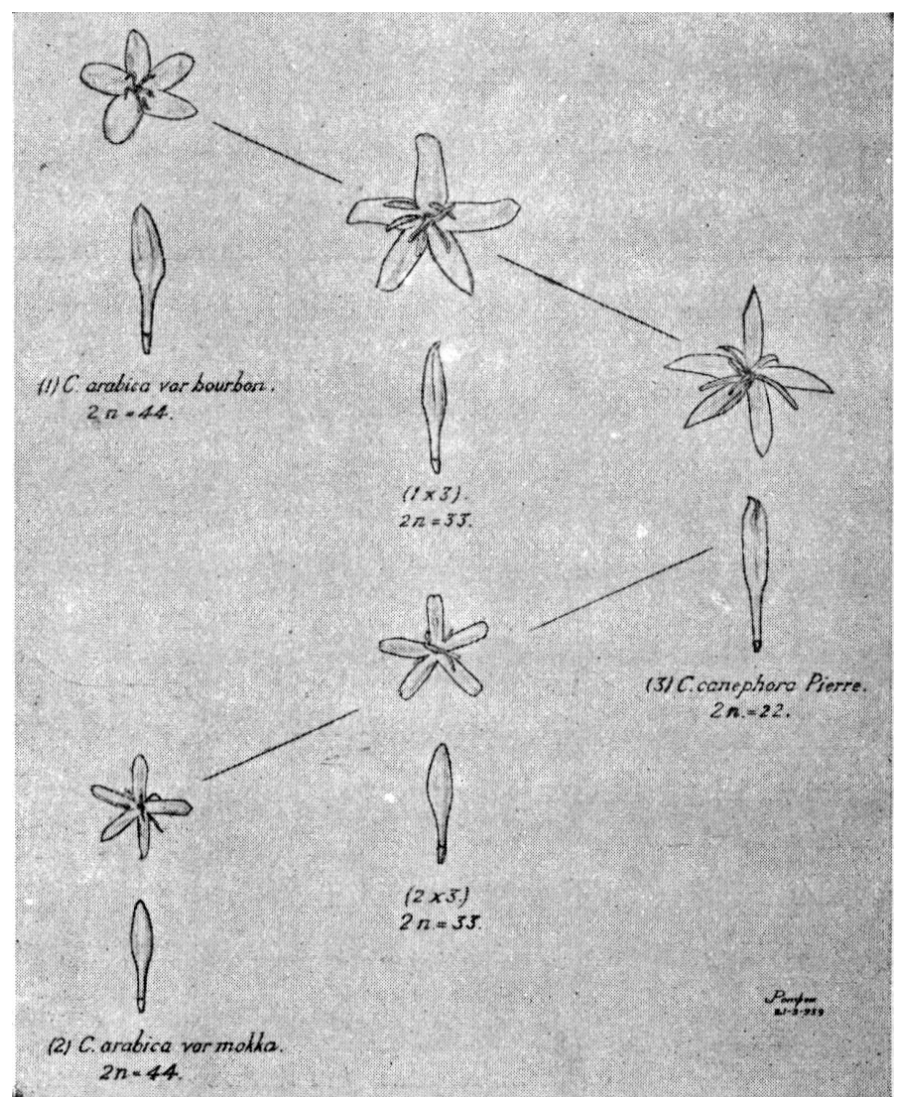

Fig. 1 
Além dos dois híbridos citados no Quadro I, um outro foi obtido pelo cruzamento do $C$. canephora com a var. murta do $C$. arabica, variedade essa caraterizada por ser heterozigota para um certo par de fatores (4) e pelas suas fôlhas pequenas. Os caracteres morfológicos dêsse híbrido são muito semelhantes aos do híbrido obtido pelo cruzamento do $C$. arabica var. bourbon com C. canephora.

Os resultados obtidos nestes cruzamentos interespecíficos são principalmente de interêsse genético e por êsse motivo serão relatados em futuras publicações sôbre genética de Coffea.

Todos estes híbridos interespecíficos têm florescido abundantemente, sendo as flores normalmente desenvolvidas, mas foi pràticamente nulo o número de frutos que chegaram a se formar.

\section{III - OBSERVAÇÕES CITOLÓGICAS NO TRIPLÓIDE DE COFFEA}

\section{a) Material e métodos}

Para o estudo da microsporogênese, botões foram fixados de um único híbrido [(45 x 37)-1], em uma solução de três partes de álcool e uma de ácido acético, sendo usado para coloração do material o método do carmim acético.

Os desenhos foram feitos com o auxílio de uma câmara clara, usando um aumento de 3350 vêzes; usou-se objetiva de imersão 100x e ocular $20 \mathrm{x}$, ambas Zeiss ; as figuras 15 a 18 foram, para reprodução, reduzidas a $1 / 4$.

\section{b) Microsporogênese}

Os estados iniciais da profase observam-se com dificuldade, pois os filamentos cromáticos não aparecem claramente. Neste estado, nota-se que a maior parte dêles se condensa perto de um nucléolo relativamente grande. Gradualmente, o filamento começa a se expandir pelo núcleo ; mas, enquanto o nucléolo é visível, uma boa parte dos filamentos conserva-se mais ou menos ligada a êle (Fig. 2). Os cromonemas aparecem como meras linhas pontilhadas.

Neste estado inicial, o núcleo da C. M.P. (*) conserva sua forma normal arredondada, colorindo-se, porém, menos intensamente do que o citoplasma envolvente.

O volume da célula aumenta e o seu citoplasma se torna menos denso colorindo-se mais levemente, quando os filamentos começam a se

(*) Cólula mãe do pólen. 
mostrar mais claramente. Fazendo-se uma pressão sôbre a lamínula, o carioplasma e o citoplasma se confundem e os filamentos se espalham e se separam melhor, verificando-se, então, algumas vêzes, claramente a duplicidade de alguns dêsses filamentos (Fig. 3). O pareamento é difícil de ser observado, na rnaior parte das células, devido à condensação dos filamentos junto ao nucléolo. Pode-se notar claramente, entretanto, que o pareamento dos filamentos se torna gradualmente mais freqùente e também que algumas vêzes um terceiro filamento tende a se prender a um par de cromosômios; aparentemente, esta tendência é mais pronunciada nas regiões em que os filamentos não estão intimamente ligados.

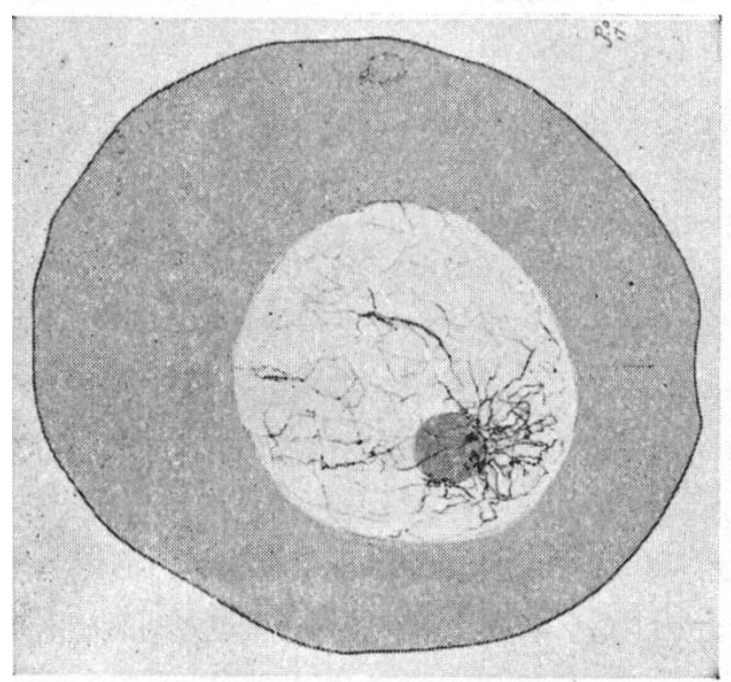

Fig. 2

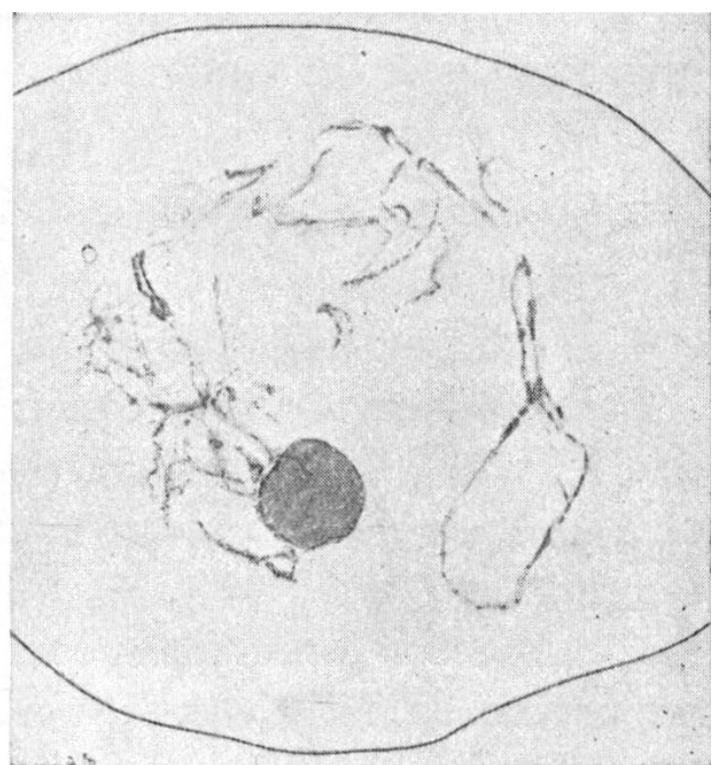

Fig. 3

Os filamentos cromáticos começam a se contrair e os cromosômios se tornam mais curtos e mais grossos; devido, provàvelmente, à contração mais intensa em alguns pontos do que em outros, êles aparecem mais fortemente coloridos aquí e alí, ao longo do seu comprimento (Fig. 4). Como esta contração é terminal para alguns cromosômios e subterminal ou mediana para outros, certas regiões dos cromosômios aparecem neste estado fortemente coloridas, a parte restante quase desaparecendo e se confundindo com o plasma (Fig. 5).

Neste estado de contração o nucléolo permanece visível e os cromosômios se mostram em grupos bem definidos uni-, bi- e trivalentes. Estes atingem seu máximo de contração ao passar de diaquinese à metáfase, quando os univalentes tomam uma forma arredondada.

$O$ Quadro II indica a freqùência dos grupos uni-,bi- e trivalentes em diaquinese e metáfase, de 15 C. M. P. examinadas. Parece que na 
Fig. 4

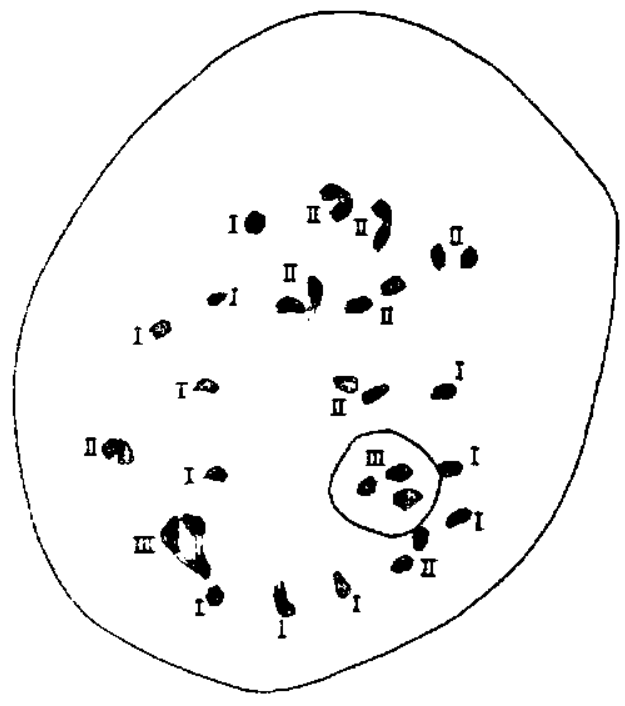

Fig. 5

passagem de um para outro dos estados acima mencionados, os elementos que se achavam unidos não se separam uns dos outros. Os univalentes que se apresentarem neste momento, devem, portanto, ser considerados como cromosômios asinapticos, isto é, que não entraram em sinapsis nos primeiros estados da divisão.

Quadro II

\begin{tabular}{c|c|c|c|c|c|c|c|c|c}
\hline \multicolumn{4}{c|}{ P R O F A S E S } & \multicolumn{6}{c}{ M E T Á F A S E S } \\
\hline Células & $\begin{array}{c}\text { Uni- } \\
\text { valen- } \\
\text { tes }\end{array}$ & $\begin{array}{c}\text { Bi- } \\
\text { valen- } \\
\text { tes }\end{array}$ & $\begin{array}{c}\text { Tri- } \\
\text { valen- } \\
\text { tes }\end{array}$ & $\begin{array}{c}\text { Bi+tri- } \\
\text { valen- } \\
\text { tes }\end{array}$ & Células & $\begin{array}{c}\text { Uni- } \\
\text { valen- } \\
\text { tes }\end{array}$ & $\begin{array}{c}\text { Bi- } \\
\text { valen- } \\
\text { tes }\end{array}$ & $\begin{array}{c}\text { Tri- } \\
\text { valen- } \\
\text { tes }\end{array}$ & $\begin{array}{c}\text { Bi+tri- } \\
\text { valen- } \\
\text { tes. }\end{array}$ \\
\hline \multirow{2}{*}{ A } & 11 & 11 & 0 & 11 & $\mathrm{H}$ & 6 & 9 & 3 & 12 \\
$\mathrm{~B}$ & 11 & 8 & 2 & 10 & $\mathrm{I}$ & 7 & 7 & 4 & 11 \\
$\mathrm{C}$ & 11 & 8 & 2 & 10 & $\mathrm{~J}$ & 8 & 8 & 3 & 11 \\
$\mathrm{D}$ & 9 & 6 & 4 & 10 & $\mathrm{~K}$ & 6 & 6 & 5 & 11 \\
$\mathrm{E}$ & 12 & 6 & 3 & 9 & $\mathrm{~L}$ & 9 & 6 & 4 & 10 \\
$\mathrm{~F}$ & 16 & 7 & 1 & 8 & $\mathrm{M}$ & 17 & 5 & 2 & 7 \\
$\mathrm{G}$ & 17 & 5 & 2 & 7 & $\mathrm{~N}$ & 29 & 2 & 0 & 2 \\
& - & - & - & - & 0 & 33 & 0 & 0 & 0 \\
\hline 7 & 87 & 51 & 14 & 65 & 8 & 115 & 43 & 21 & 64 \\
\hline Média & 12,4 & 7,3 & 2,0 & 9,3 & Média & 14,4 & 5,4 & 2,6 & 8,0 \\
\hline
\end{tabular}

N. ${ }^{\circ}$ total de cromosômios

$\%$ de bivalentes

$\%$ de trivalentes

$\%$ de bi-trivalentes
231

43,3

18,2

61,5
N. ' total de cromosômios

$\%$ de bivalentes

$\%$ de trivalentes

$\%$ de bi--trivalentes
264

32,6

23,9

56,5 
As figuras 5 e 6 mostram dois casos de diaquinese, 0 primeiro com lli, 8II e 2III, e o segundo com lli e llir.

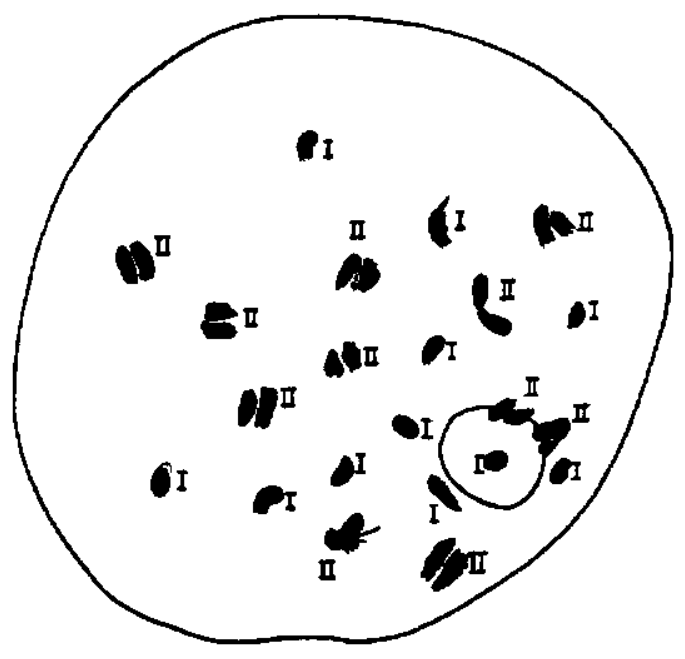

Fig. 6

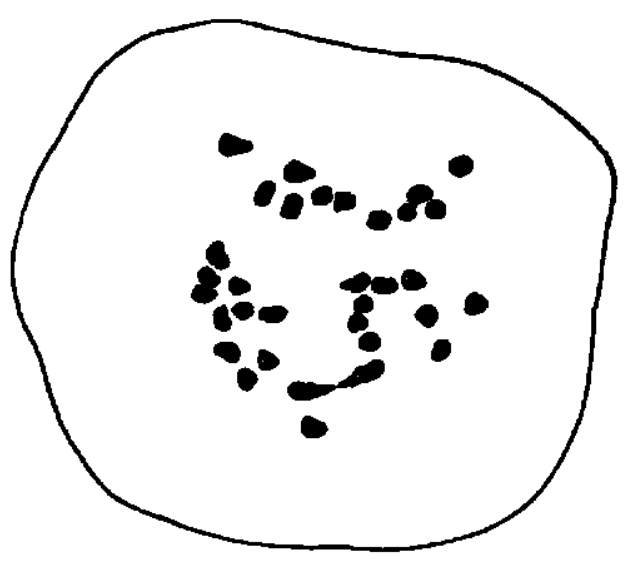

Fig. 7

A Fig. 7 representa uma metáfase com 29r e 2II ; é interessante notar nesta figura os cromosômios arranjados em três grupos de onze. Uma outra metáfase pode-se ver na Fig. 8, onde 33 univalentes se distribuem em dois grupos, um com 12 e outro com 21 cromosômios.

Sem se dividir, os univalentes passam para os polos logo no início da anáfase, distribuindo-se aparentemente ao acaso, sendo retardado o movimento dos bi- e trivalentes, como se vê na Fig. 9. A distribuição dêstes elementos é extremamente irregular, sendo que algumas vêzes

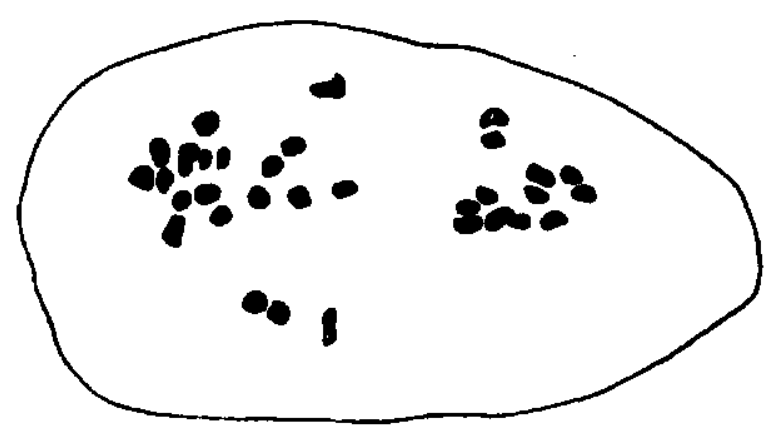

Fig. 8 


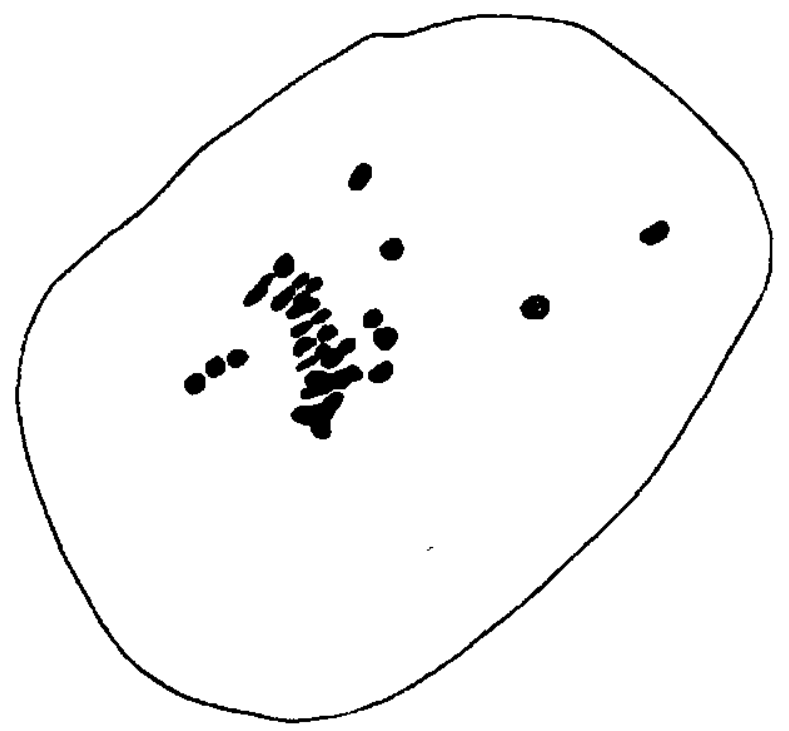

Fig. 9

ambos os constituintes de um mesmo grupo bivalente passam para um mesmo polo, como pode ser observado na Fig. 10.

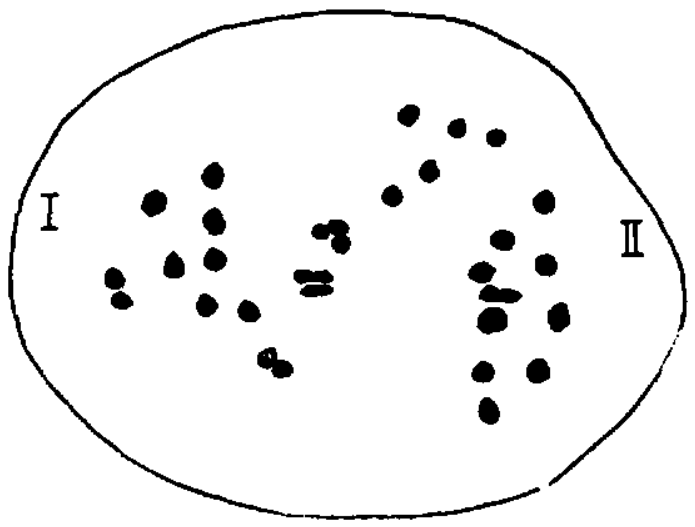

Fig. 10

Alguns dêstes elementos se atrasam de tal forma, que não chegam a se incluir nos dois núcleos filhos resultantes dessa primeira divisão, passando, mais tarde, a formar micro-núcleos. O mesmo acontece, às vêzes, para algum cromosômio univalente atrasado.

No Quadro III é dada a distribuição dos cromosômios, observada em 37 células anafásicas; nota-se que há uma certa tendência para a formação de núcleos filhos com, aproximadamente, metade do número somático de cromosômios, isto é, com 16 e com 17 cromosômios. Entretanto, devido a irregularidades que se observam durante a sua distribuição, retardando alguns dêles em sua marcha para os polos, sòmente $54 \%$ dos núcleos-filhos contém estes números. 
Quadro III

\begin{tabular}{c|c|c|c}
\hline Polo 1 & "Laggers" & Polo 2 & N. ${ }^{\circ}$ de células \\
\hline 15 & 2 & 16 & 9 \\
16 & 0 & 17 & 6 \\
15 & 1 & 17 & 5 \\
16 & 1 & 16 & 3 \\
14 & 3 & 16 & 2 \\
13 & 4 & 16 & 2 \\
15 & 0 & 18 & 2 \\
14 & 2 & 17 & 1 \\
14 & 1 & 15 & 1 \\
15 & 3 & 17 & 1 \\
13 & 3 & 16 & 1 \\
12 & 5 & 17 & 1 \\
11 & 5 & 19 & 1 \\
13 & 0 & 255 & 37 \\
11 & 3 & & 1 \\
\hline 207 & 33 & & \\
\hline
\end{tabular}

Uma vacuolização dos cromosômios e a formação de núcleos telofásicos contendo um ou mais nucléolos, ocorrem, às vêzes, logo após a $1 .{ }^{a}$ anáfase, como se vê nas figuras 11 e 12 . Mais comumente, entretanto, os cromosômios não passam for estas mudanças e iniciam a 2. ${ }^{a}$ divisão.

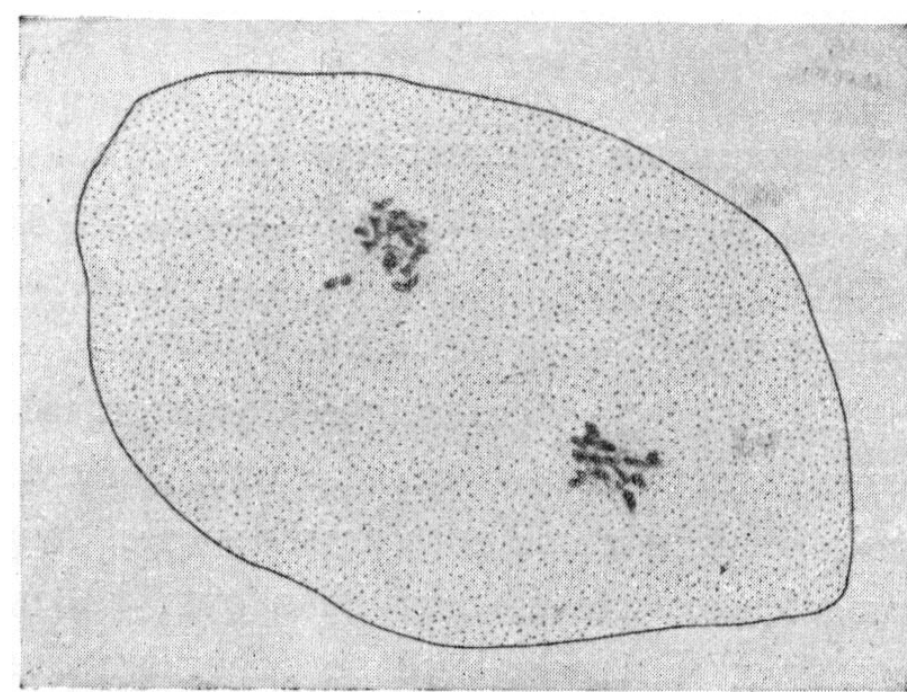

Fig. 11 


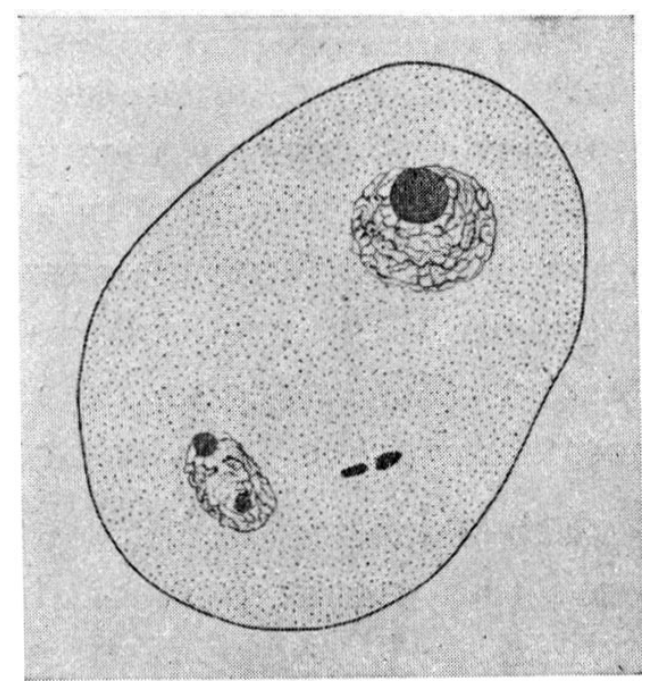

Fig. 12

Não sabemos se uma 2." divisão realmente se dá quando núcleos telofásicos se formam no fim da $l^{a}$ divisão ; é possível, entretanto, formarem-se diades de pólen em vez de tetrades em tais casos. Examinando-se, porém, cêrca de 400 microsporocitos, nenhuma diade foi encontrada.

A frequêencia dos "laggers" na 2." divisão é menor que na primeira ; em $43 \%$ das divisões observadas, os cromosômios se partem e suas metades são uniformemente distribuidas para os polos. A fig. 13 dá um exemplo da 2. ${ }^{\mathrm{a}}$ divisão: em um dos polos, veem-se 11 cromosômios

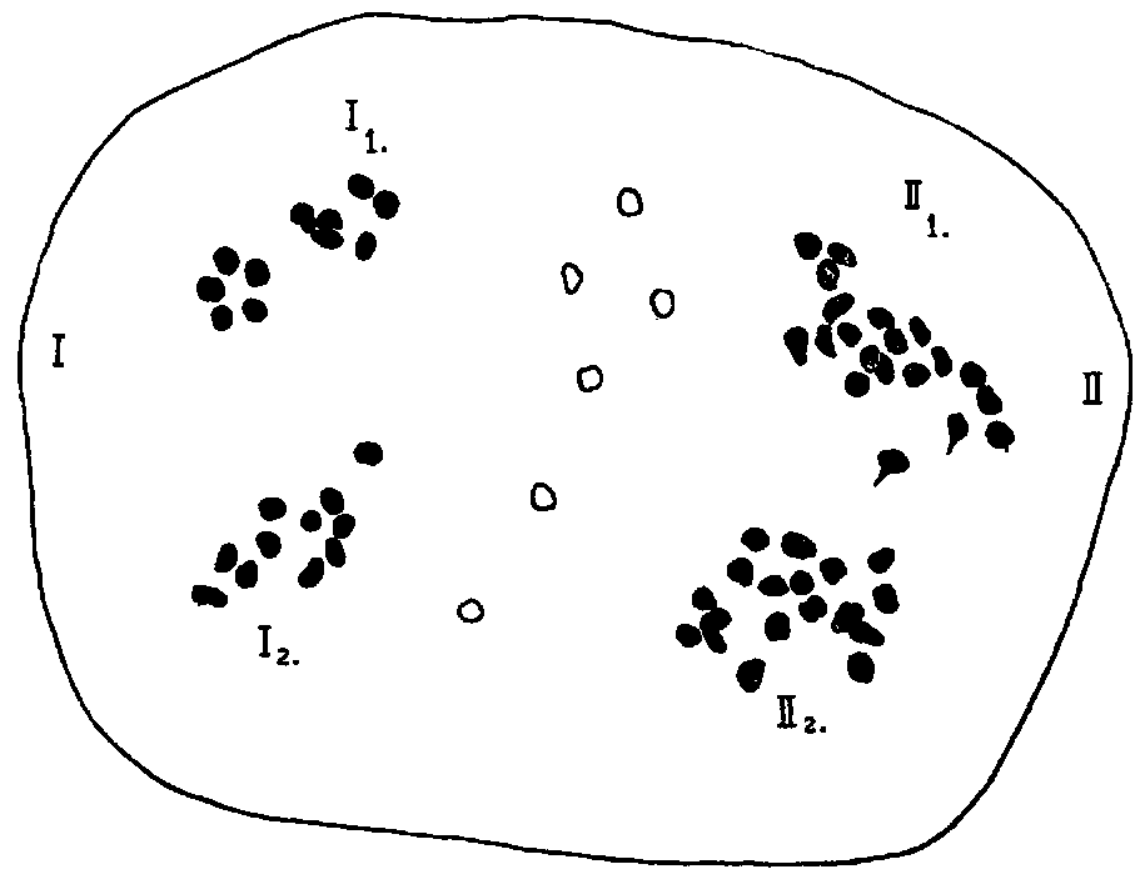

Fig. 13 
caminhando para cada lado; no outro polo, 20 cromosômios vão para um lado e 18 para outro; além disso, notam-se 6 cromosômios entre os polos I e II. Como o número dos cromosômios nos polos é de 30, estes 6 cromosômios devem ter-se originado de 3 que não caminharam para os polos na 1.a divisão e que se dividiram mais tarde. Numa outra figura semelhante, aproximadamente a mesma distribuição dos cromosômios foi verificada, com a única diferença que, num dos polos, 19 cromosômios dividiram-se normalmente na 2: divisão.

Em consegùência destas anormalidades, resultam, da 2." divisão, núcleos, tendo, em geral, num número menor de cromosômios do que

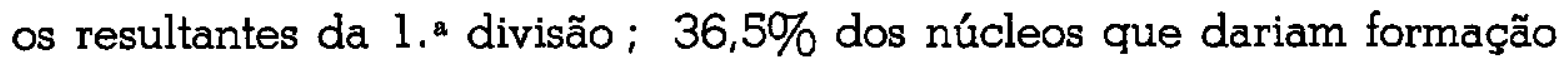
aos microsporos, revelaram possuir 15 ou 16 cromosômios. Sòmente 9,5\% dêstes núcleos possuiam 11 cromosômios, não tendo sido encontrado nenhum com 22.

O Quadro IV apresenta a distribuição em 21 células examinadas dos cromosômios na 2." anáfase, e o Quadro V contém o resumo dêstes dados, para pôr em destaque as frequências das diferentes distribuições.

\section{Quadro IV}

\begin{tabular}{|c|c|c|c|c|c|c|}
\hline \multicolumn{3}{|c|}{ 2." Anáfase no Polo I } & \multirow{2}{*}{$\begin{array}{c}\text { "Laggers" } \\
\text { da } 1 . \text { "Anáfase }\end{array}$} & \multicolumn{3}{|c|}{ 2." Anáfase no Polo II } \\
\hline Polo $I_{1}$ & "Laggers" & Polo $I_{2}$ & & Polo $\mathrm{II}_{1}$ & "Laggers" & PoIo $\mathrm{Il}_{2}$ \\
\hline $\begin{array}{l}18 \\
13 \\
17 \\
17 \\
19 \\
20 \\
15 \\
16 \\
16 \\
16 \\
16 \\
16 \\
16 \\
16 \\
15 \\
12 \\
13 \\
17 \\
15 \\
14 \\
13\end{array}$ & $\begin{array}{l}- \\
- \\
z \\
z \\
- \\
- \\
\frac{1}{1} \\
\frac{1}{-} \\
\frac{1}{1}\end{array}$ & $\begin{array}{l}20 \\
13 \\
17 \\
15 \\
19 \\
18 \\
17 \\
18 \\
16 \\
14 \\
16 \\
16 \\
17 \\
15 \\
15 \\
14 \\
13 \\
17 \\
15 \\
14 \\
13\end{array}$ & $\begin{array}{c}4 \\
4 \\
5 \\
1+(1 \rightarrow 2) \\
3 \longrightarrow 6 \\
3 \rightarrow 6 \\
2 \\
3 \\
5 \\
2 \\
4 \\
2 \\
3 \\
0 \\
4 \\
0 \\
2 \\
4 \\
4 \\
3 \\
3\end{array}$ & $\begin{array}{l}11 \\
16 \\
11 \\
15 \\
11 \\
11 \\
15 \\
12 \\
10 \\
15 \\
12 \\
14 \\
12 \\
16 \\
13 \\
19 \\
- \\
- \\
-\end{array}$ & $\begin{array}{l}- \\
- \\
- \\
- \\
\bar{z} \\
2 \\
1 \\
2 \\
3 \\
- \\
- \\
- \\
-\end{array}$ & $\begin{array}{l}9 \\
16 \\
11 \\
15 \\
11 \\
11 \\
15 \\
14 \\
12 \\
15 \\
13 \\
14 \\
13 \\
15 \\
13 \\
21 \\
- \\
- \\
-\end{array}$ \\
\hline
\end{tabular}


Quadro V

\begin{tabular}{c|c|c|c|c|c|c|c|c|c|c|c|c|c|c}
\hline $\begin{array}{c}\text { N.॰ de } \\
\text { cromosômios }\end{array}$ & 9 & 10 & 11 & 12 & 13 & 14 & 15 & 16 & 17 & 18 & 19 & 20 & 21 & Total \\
\hline Fregùência & 1 & 1 & 7 & 5 & 10 & 7 & 14 & 13 & 7 & 3 & 3 & 2 & 1 & 74 \\
\hline
\end{tabular}

Como mencionámos acima, os "laggers" resultantes da $1 .{ }^{\text {a }}$ divisão dividem-se, algumas vêzes, durante a $2 .^{a}$ Anáfase, mas não se incluem em nenhum dos quatro principais núcleos formados; estes cromosômios não se dispõem regularmente em uma placa equatorial, e nem se vê um fuso junto aos mesmos (Fig. 13).

A Fig. 14 mostra um outro aspecto da $2 .{ }^{a}$ divisão. $O$ arranjo dos cromosômios nesta célula pode ter-se originado do modo seguinte: na 1." divisão 15 cromosômios foram para um polo, 16 para o outro e 2 se perderam no citoplasma; na 2." divisão, um outro cromosômio se perdeu em um dos polos, passando 14 para cada lado; no outro polo, 15 cromosômios foram para um lado e 16 para outro, um dêles sem se dividir.

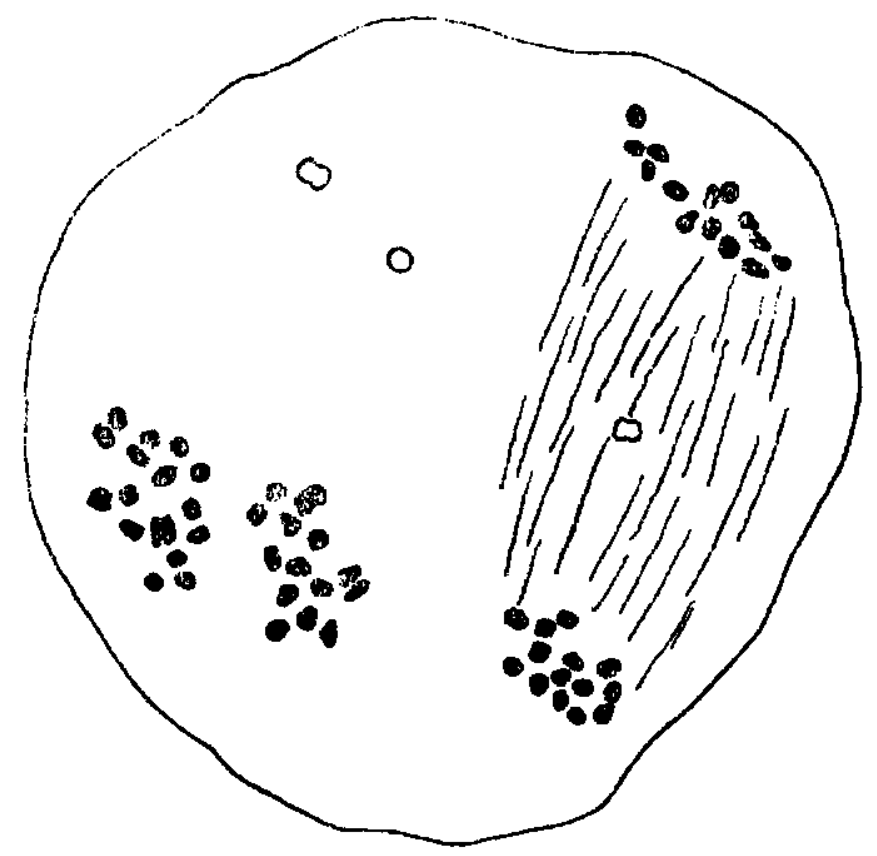

Fig. 14

Microcitos contendo I a 10 cromosômios são formados como consequência do comportamento anormal de alguns dos cromosômios; a viabilidade dêstes microcitos, é, entretanto, muito duvidosa. 
O citoplasma se divide no fim da 2." divisão, formando-se as "tetrades" ; como era de se esperar, estas são quase sempre anormais, contendo mais de 4 microsporos (Figs. 15 a 18).

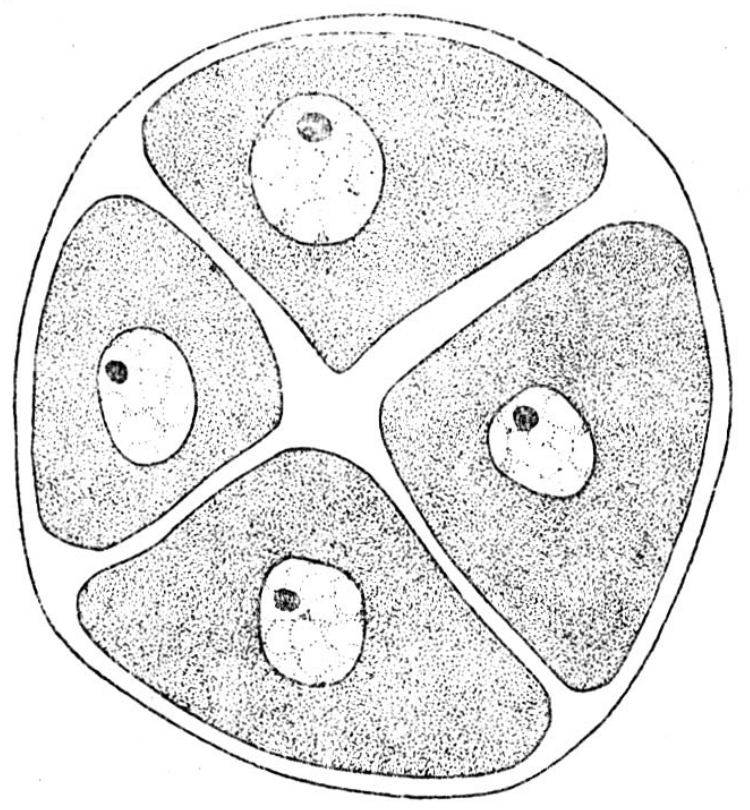

Fig. 15

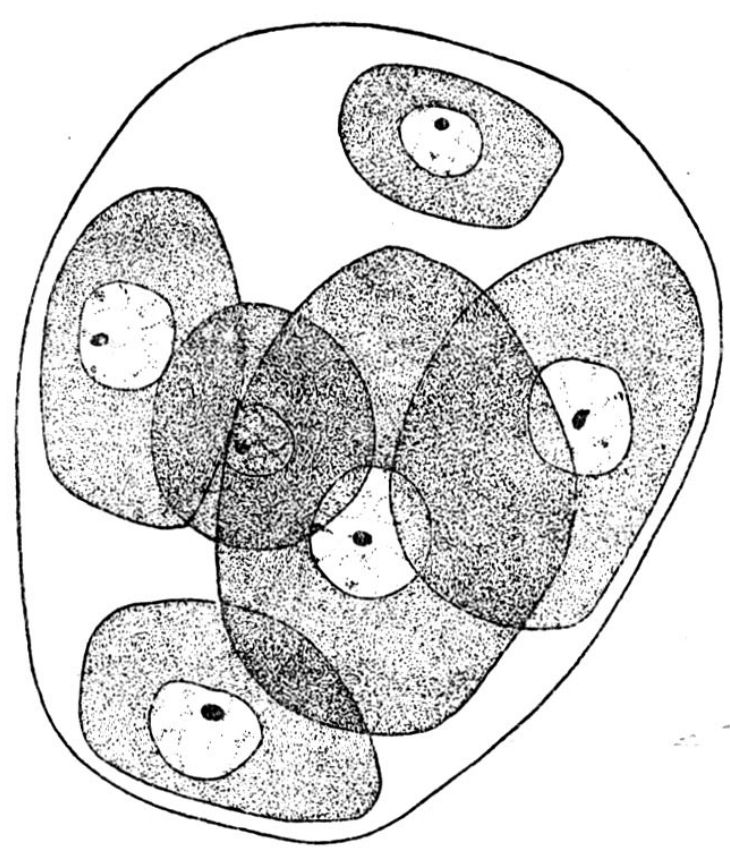

Fig. 17

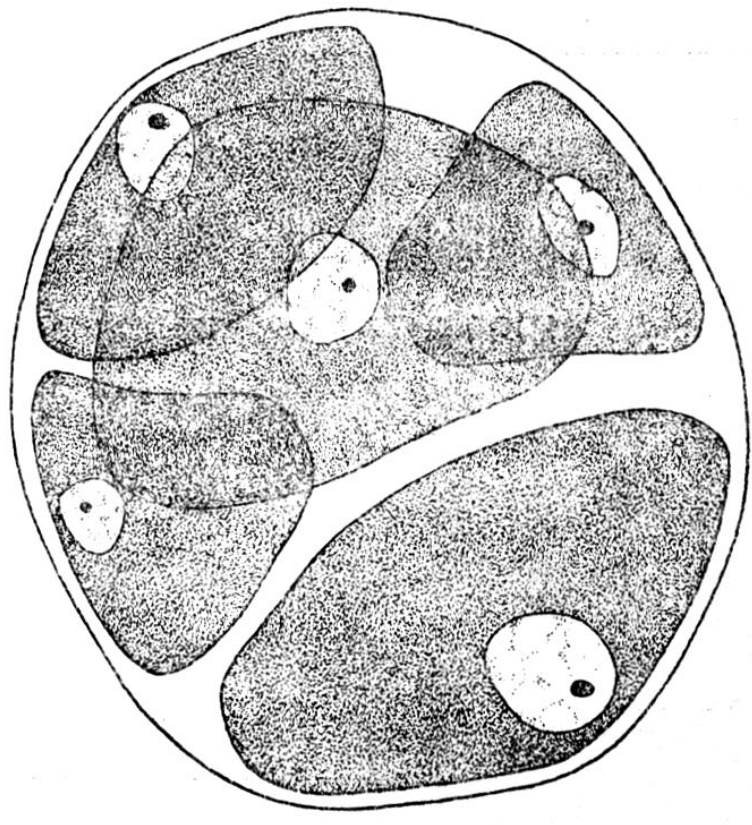

Fig. 16

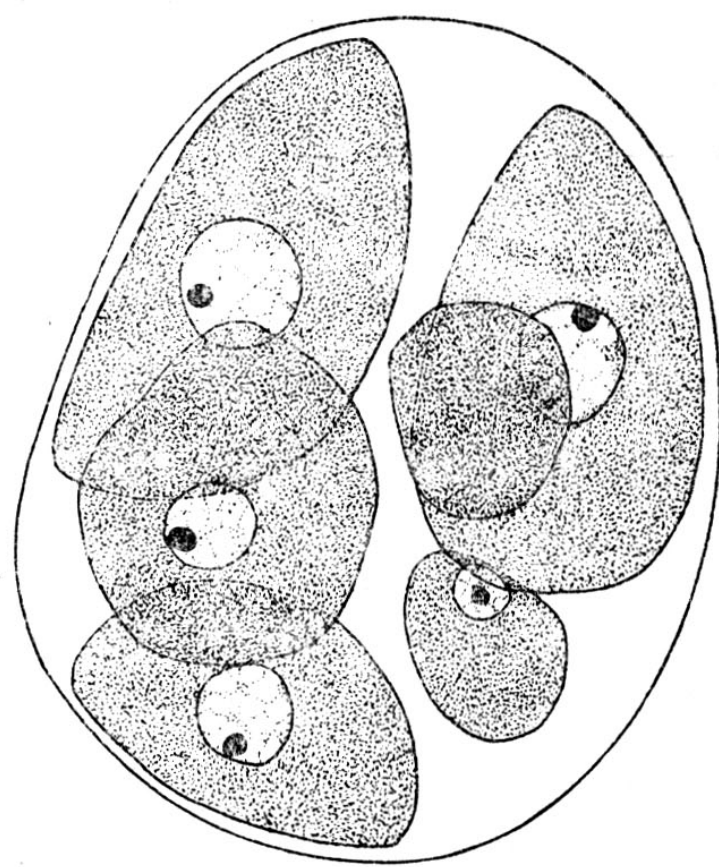

Fig. 18

Uma contagem dos microsporos formados por 400 microsporocitos, deu os resultados que se encontram no Quadro. VI. 


\section{Quadro VI}

Números de microsporos formados por "tetrade"

\begin{tabular}{c|c|c|c|c|c|c|c}
\hline $\begin{array}{c}\text { N. }{ }^{\circ} \text { de } \\
\text { microsporos }\end{array}$ & 4 & 5 & 6 & 7 & 8 & 9 & Total \\
\hline \begin{tabular}{c|r|r|r|r|r} 
Frequência \\
$\%$
\end{tabular} & 26.3 & 48.8 & 21.5 & 2.7 & 0.5 & 0.2 & 100 \\
\hline
\end{tabular}

c) Caracteres dos grãos de pólen

Como resultado da grande variabilidade do número de microsporos formados a partir de cada microsporocito, o tamanho dos grãos de pólen é também extremamente variável. 200 grãos de pólen foram medidos, verificando-se para êles um diâmetro médio de $27,58 \pm 6,66 \mu$, com uma variação de 8 a $48 i \iota(C=24,18 \%)$.

Em artigo anterior (3) foram publicados dados sôbre o tamanho e a variabilidade dos grãos de pólen de 3 variedades de $C$. arabica, uma tetraplóide, uma hexaplóide e uma octoplóide; para efeito de comparação de sua variabilidade, reunimos a seguir estes dados juntamente com os do híbrido triplóide:

\begin{tabular}{l|c|c|c}
\hline \multicolumn{1}{c|}{ Espécie ou híbrido } & 2n & $\begin{array}{c}\text { Diâmetro do grão de } \\
\text { polen } \\
\text { (dimensöes máximas) }\end{array}$ & $\begin{array}{c}\text { Coeficiente } \\
\text { de } \\
\text { variabilidade }\end{array}$ \\
\hline & 44 & 28 a $44 \mu$ & $8,0 \%$ \\
C. arabica & 66 & 28 a $60 \mu$ & $12,6 \%$ \\
C. arabica & 88 & 24 a $56 \mu$ & $12,0 \%$ \\
C. arabica & 83 & 8 a $48 \mu$ & $24,2 \%$ \\
C. arabica x C. canephora & 33 & \\
\hline
\end{tabular}

A despeito das anormalidades que se constatam na meiose das variedades hexa- e octoplóides, verifica-se que a variabilidade do tamanho dos grãos de pólen é muito maior no híbrido triplóide.

Experiências de germinação com grãos de pólen do triplóide, indicaram-nos que êle é estéril em bem alta porcentagem; em idênticas condições, conseguimos fazer com que germinassem $90 \%$ dos grãos de pólen do tetraplóide normal (C. arabica). 


\section{IV -- RESULTADOS DE AUTOFECUNDAÇÕES E CRUZAMENTOS DO TRIPLÓIDE}

Grande número de flores dos híbridos triplóides foi protegido com sacos de papel para efeito de auto-polinização, mas só um pequeno número de frutos foi obtido; estes, em geral, não se apresentavam bem arredondados como os normais e sòmente alguns continham sementes, às vêzes muito irregulares e com embrião muito anormal; nenhuma dessas sementes chegou a germinar.

Ao mesmo tempo, muitas flores foram castradas e polinizadas com pólen de $C$. arabica e $C$. canephora, não se conseguindo obter nenhuma semente.

Como os triplóides, que se achavam rodeados por cafeeiros pertencentes a espécies e variedades de constituição citológica variada, floresceram abundantemente ao mesmo tempo que êsses outros cafeeiros, formaram-se nessas plantas triplóides alguns poucos frutos encerrando sementes aparentemente normais. Obtiveram-se duas plantas dessas sementes [da planta $(45 \times 37)-1$ ], que revelaram ter $2 \mathrm{n}=44$ cromosômios. Bem poucos dêsses cromosômios parecem ser do tipo canephora.

\section{$\mathrm{V}$ - DISCUSSÃO E CONCLUSÕES}

Como era de se esperar, a meiose do híbrido interespecífico triplóide $C$. arabica $\times$. canephora é bastante anormal, resultando daí a formação de grãos de pólen estéreis, com números variáveis de cromosômios. É muito provável que o mesmo comportamento anormal dos cromosômios notado na microsporogênese ocorra também na megasporogênese. A conhecida esterilidade de alguns dos híbridos interespecíficos existentes em Java, tem assim esclarecida a sua causa.

Com respeito ao comportamento dos cromosômios na meiose, al. gumas conclusões interessantes podem ser tiradas. Até o presente, nada se sabe sôbre as relações genéticas que ligam as várias espécies do gênero Coffea, e sôbre a origem de alguns tipos cultivados. $\bigcirc$ híbrido triplóide que estudámos, contém um grupo de 11 cromosômios de $C$. canephora e outro de 22 de $C$. arabica; o fato de ocorrer um pareamento dos cromosômios no início da profase numa média de cêrca de $61,5 \%$, indica que existe uma certa homologia entre vários dos cromosômios; devido ao fato de serem alguns cromosômios do grupo canephora mais longos que os do arabica, e levando-se em conta que C. arabica é considerada como uma espécie tetraplóide, é provável que na maior 
parte dos casos ocorra autosinapsis entre os cromosômios do grupo arabica. Todavia, não possuimos dados para falar sôbre a ocorrência de alosinapsis.

Se a espécie $C$. arabica fôsse autotetraplóide, seria freqùente a existência de caracteres determinados por pares de gens em duplicata ; entretanto, as análises genéticas em estudo, revelam que a maior parte dos principais caracteres, até agora analisados, é determinada por pares simplez de gens. Se a hipótese de uma origem autotetraplóide for confirmada por novas análises genéticas e citológicas, deve-se supor que a duplicação dos cromosômios se deu em tempos muito remotos.

A ocorrência de trivalentes na profase e metáfase sugere uma certa homologia entre os cromosômios das espécies arabica e canephora, pois não é provável a associação de 3 elementos do grupo arabica e nem - pareamento de elementos do grupo canephora. Pode ser que certas regiões de alguns dos cromosômios canephora sejam análogas a outras existentes em outros cromosômios do arabica; pode ser, porém, que a associação de um terceiro elemento a um grupo de dois, seja meramente devida à atração que exercem entre si, as regiões inertes, $\left(\begin{array}{lll}1 & e\end{array}\right)$. Os dados obtidos até agora, são muito incompletos para que se possa falar sôbre as rəlações genéticas entra as duas espécies cruzadas.

Com relação à constituição citológica das duas plantas obtidas de um dos híbridos triplóides, podem ser feitas as seguintes considerações : ambas têm $2 n=44$ cromosômios e aparentemente alguns de seus cromosômios derivam-se do $C$. canephora. Essas plantas estão ainda muito pequenas e, assim, nada se pode dizer ainda sôbre os seus caracteres morfológicos. Como já foi dito, elas são originárias de sementes formadas por flores não protegidas. Analisando o Quadro V, pode-se concluir que elas dificilmente se teriam originado por auto-polinização, pois apenas um núcleo com $\mathbf{n}=21$ foi encontrado entre 74 formados após a 2." telofase. É bastante improvável, portanto, que, pela auto-polinização, se associem dois gametas cuja soma de səus cromosômios seja $2 n=44$. Levando-se em consideração a polinização cruzada, convém salientar que grãos de pólen das plantas vizinhas ao triplóide com $\mathrm{n}=$ 22 e 33 cromosômios foram produzidos em abundância. Os grãos de pólen com $\mathbf{n}=11$ possivelmente não fertilizaram $\circ$ triplóide porque êle, provàvelmente, não produz gametas com 33 cromosômios. Dos outros dois tipos de pólen, aquele com $\mathbf{n}=22$ certamente foi o fertilizador, porquanto era o que, com maior abundância, existia ao lado do triplóide, pois a única planta hexaplóide, da qual se origina uma 
pequena porcentagem de grãos de pólen com $\mathbf{n}=33$, floresceu muito pouco. Um estudo futuro da meiose nestas duas plantas filhas, esclarecerá a sua constituição citológica.

\section{V - SUMÁRIO}

1. É dada uma pequena descrição dos principais caracteres morfológicos de dois híbridos interespecíficos triplóides (C. arabica $\mathrm{x}$ C. canephora); seu crescimento é normal e a forma e tamanho das fôlhas e das flores intermediários entre as duas espécies.

2. A microsporogênese é dada em detalhe; esperadas anormalidades foram observadas na distribuição dos cromosômios na $1 .{ }^{a}$ e na $2 .^{a}$ divisão, resultando a formação de grãos de pólen estéreis, extremamente variáveis em tamanho.

3. Acredita-se que anormalidades análogas ocorram também na megasporogênese.

4. Ficaram confirmadas as prováveis causas da esterilidade de alguns híbridos interespecíficos obtidos em Java, que já haviam sido sugeridas em artigos anteriores.

5. O íntimo pareamento de alguns cromosômios na profase e mesmo na metáfase, sugere a possível origem autotetraplóide da espécie Colfea arabica.

6. A formação de trivalentes na profase e na metáfase, sugere que alguns dos cromosômios da espécie canephora devem ter regiões análogas a outros da espécie arabica. Nada pode ser dito, entretanto, sôbre as possíveis relações genéticas entre $C$. arabica e $C$. canephora.

7. Duas plantas provenientes de sementes de um triplóide e obtidas de flores nas quais a polinização não foi controlada, possuem $2 \mathbf{n}=44$ cromosômios. É sugerido que se tenham derivado de células-ovo do triplóide com 22 cromosômios, que foram fertilizadas por grãos de pólen com 22 cromosômios, provenientes de plantas arabica cultivadas ao redor do triplóide.

\section{LITERATURA CITADA}

1. Kostoff, D. \& Arutiunian, N. "Heterochromatic (inert) regions in the chromosomes of Crepis capillaris." Nature, Lond., 141 : 514-15. 1938.

2. Kostoff, D. "Heterochromatin at the distal ends of the chromosomes in Triticum monococcum." Nature, Lond., 141: 690-1. 1938.

3. Krug, C. A. "Cytological observations in Colfea. III." I. Genet. 34 : 399-414. 1937.

4. - $\quad$ "The genetics of Colfea. Part I. The inheritance of a dwarf type -.- nana." J. Genet. 37 : 41-50. 1938. 